\title{
Risk factors of age-related macular degeneration in Argentina
}

\section{Fatores de risco para degeneração macular relacionada à idade na Argentina}

María Eugenia Nano ${ }^{1}$, Van Charles Lansingh ${ }^{2}$, María Soledad Pighin ${ }^{3}$, Natalia Zarate ${ }^{1}$, Hugo Nano ${ }^{2}$, Marissa Janine Carter ${ }^{4}$, João Marcello Furtado ${ }^{5}$, Clelia Crespo Nano ${ }^{1}$, Luciana Fiocca Vernengo ${ }^{6}$, José Domingo Luna ${ }^{6}$, Kristen Allison Eckert ${ }^{4}$

\section{ABSTRACT}

Purposes: To assess the risk factors of age-related macular degeneration in Argentina using a case-control study.

Methods: Surveys were used for subjects' antioxidant intake, age/gender, race, body mass index, hypertension, diabetes (and type of treatment), smoking, sunlight exposure, red meat consumption, fish consumption, presence of age-related macular degeneration and family history of age-related macular degeneration. Main effects models for logistic regression and ordinal logistic regression were used to analyze the results.

Results: There were 175 cases and 175 controls with a mean age of 75.4 years and 75.5 years, respectively, of whom 236 (67.4\%) were female. Of the cases with age-related macular degeneration, 159 (45.4\%) had age-related macular degeneration in their left eyes, $154(44.0 \%)$ in their right eyes, and $138(39.4 \%)$ in both eyes. Of the cases with age-related macular degeneration in their left eyes, $47.8 \%$ had the dry type, $40.3 \%$ had the wet type, and the type was unknown for $11.9 \%$. The comparable figures for right eyes were: $51.9 \%, 34.4 \%$, and $13.7 \%$, respectively. The main effects model was dominated by higher sunlight exposure (OR [odds ratio]: 3.3) and a family history of age-related macular degeneration (OR: 4.3). Other factors included hypertension (OR: 2.1), smoking (OR: 2.2), and being of the Mestizo race, which lowered the risk of age-related macular degeneration (OR: 0.40). Red meat/fish consumption, body mass index, and iris color did not have an effect. Higher age was associated with progression to more severe age-related macular degeneration.

Conclusion: Sunlight exposure, family history of age-related macular degeneration, and an older age were the significant risk factors. There may be other variables, as the risk was not explained very well by the existing factors. A larger sample may produce different and better results.

Keywords: Age-related macular degeneration; Risk factors; Sunlight exposure; Family history; Argentina; Case-control study

\section{RESUMO}

Objetivo: Determinar os fatores de risco para degeneração macular relacionada à idade na Argentina utilizando um estudo caso-controle.

Métodos: Questionários foram usados para a obtenção de informações dos participantes em relação à ingesta de antioxidantes, idade/sexo, raça, índice de massa corporal, hipertensão, diabetes (e tipo de tratamento), tabagismo, exposição à luz solar, consumo de carne vermelha/peixe, presença de degeneração macular relacionada à idade e história familiar de degeneração macular relacionada à idade. Modelos de efeito principal para regressão logística e regressão logística ordinal foram usados para analisar os resultados.

Resultados: Foram recrutados 175 casos e 175 controles com uma média de idade de 75,4 anos e 75,5, respectivamente, dos quais $236(67,4 \%)$ eram mulheres. Cento e cinquenta e nove $(45,4 \%)$ tinham degeneração macular relacionada à idade em seus olhos esquerdos, 154 (44,0\%) em seus olhos direitos, e 138 (39,4\%) em ambos os olhos. Entre os casos de degeneração macular relacionada à idade no olho esquerdo, 47,8\% apresentavam o tipo seca, 40,3\% o tipo úmida, e o tipo era desconhecido em 11,9\%. Os achados para os olhos direitos foram: $51,9 \%, 34,4 \%$ e 13,7\%, respectivamente. 0 modelo de efeito principal foi dominado por maior exposição à luz solar (OR [odds ratio]: 3,3) e história familiar de degeneração macular relacionada à idade (OR: 4,3). Outros fatores incluindo hipertensão (OR: 2,1), tabagismo (OR: 2,2), e pertencente à raça mestiça, que diminuiram o risco de degeneração macular relacionada à idade $(O R: 0,40)$. Consumo de carne vermelha e de peixe, índice de massa corporal e coloração da íris não foram fatores de risco. Idade avançada foi associada com progressão para degeneração macular relacionada à idade mais grave.

Conclusão: Exposição àluzsolar, história familiar de degeneração macular relacionada à idade, e idade avançada foram os fatores de risco significativos. Podem existir outras variáveis, já que os riscos não foram bem explicados pelos fatores existentes. Um maior tamanho amostral poderia produzir resultados diferentes e melhores.

Descritores: Degeneração macular relacionada à idade; Fatores de risco; Exposição solar; História familiar; Argentina; Estudo caso-controle

\section{INTRODUCTION}

Age-related macular degeneration (AMD) causes 5\% of global blindness and $1 \%$ of visual impairment $t^{(1,2)}$. In the early stages of AMD, deposits of drusen are observed in the retina between the retinal pigment epithelium and choroid in the macular region ${ }^{(3)}$. The disease progresses to more advanced stages, leading to 2 types of late AMD: geographic atrophy of the retinal pigment epithelium and photoreceptor cells (dry AMD) and aberrant choroidal neovascularization (wet AMD), which leads to central vision loss ${ }^{(3)}$.
AMD is the leading cause of blindness among the elderly in developed countries with prevalence of late AMD at 1.2-1.7\%(4-9). While AMD has generally been a greater issue in developed countries, studies from India suggest similar prevalence (1.4-1.8\%) for late AMD as the population continues to age in developing countries ${ }^{(10,11)}$. China, on the other hand, has a considerably lower prevalence as confirmed by the Beijing Eye Study ${ }^{(12)}$.

AMD was considered untreatable until argon laser treatment and, later, photodynamic therapy were applied ${ }^{(13)}$. Today, intravitreal an-
Submitted for publication: January 17, 2013

Accepted for publication: January 31, 2013

Study carried out at Fundación Hugo Nano, Buenos Aires.

Fundación Hugo Nano, Buenos Aires, Argentina.

International Agency for the Prevention of Blindness/VISION 2020 Latin America.

${ }^{3}$ Hospital Distrital Lago Argentino "Dr José Formenti", El Calafate, Santa Cruz, Argentina.

${ }^{3}$ Hospital Distrital Lago Argentino "Dr Jose For

${ }^{4}$ Strategic Solutions, Inc., Cody, WY - USA.
${ }^{5}$ Universidade Federal de São Paulo, São Paulo, Brazil.

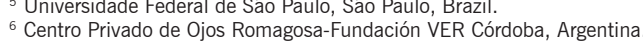

Financial support: Preparation of the manuscript was funded by ORBIS, which had no role in any aspect of the study.

Disclosure of potential conflicts of interest: M.E.Nano, employed by Fundación Hugo Nano; V.C.Lansingh, employed by the IAPB; M.S.Pighin, None; N.Zarate, employed by Fundación Hugo Nano; H.Nano, None; M.J.Carter, employed by Strategic Solutions and is a paid consultant to ORBIS and the IAPB; J.M.Furtado, None; C.C.Nano, None; L.F.Vernengo, None; J.D.Luna, employed by Centro Privado de Ojos Romagosa-Fundación VER Córdoba; K.A.Eckert, employed by Strategic Solutions.

Correspondence address: Van C. Lansingh. International Agency for the Prevention of Blindness/ VISION 2020 Latin America. 3720 San Simeon Cr. Weston, FL 33331, USA Email: vlansingh@v2020la.org 
ti-vascular endothelial growth factor (VEGF) therapy is the preferred treatment, which has decreased the annual incidence of visual impairment due to AMD by 32-50\% in some developed countries ${ }^{(13-16)}$. Anti-VEGF therapy is effective, although it does not restore vision to previous levels in the majority of subjects treated, and it requires multiple injections that are very costly ${ }^{(17)}$.

Over the past 2 decades, efforts have been made to identify associations between AMD and risk factors with varied results, but it is generally agreed that older age, female gender, Caucasian race, and family history of AMD are significant unmodifiable risk factors to developing the disease and/or progressing to late AMD and smoking might be a modifiable risk factor. An algorithm was developed to predict which subjects with early/intermediate AMD are most likely to progress to late dry/wet AMD, by assessing the following variables: 6 genetic variants, age, sex, education, baseline AMD grade, smoking, Body Mass Index (BMI), and nutritional supplement use ${ }^{(18)}$. Multivariate risk models were next modified to additionally include time varying rates of progression of up to 12 years and macular drusen size in both eyes at baseline to follow the disease progression in the Age-Related Eye Disease Study ${ }^{(19)}$. Of the 2,937 subjects who participated in study, 819 progressed to late AMD during the 12-year follow-up period. Age, smoking, BMI, genetic variants, advanced AMD in one eye and drusen size in both were independently associated with progression ${ }^{(19)}$.

In Latin America, AMD treatment is very costly, and little research has been done on the disease ${ }^{(20)}$. Approximately $8.3 \%$ of the population of Latin America and the Caribbean is 65 years or older ${ }^{(21)}$. Argentina has one of the highest elderly populations in the region with up to $13.1 \%$ being 65 years or older, and $97 \%$ of the population of Argentina is White (mainly of Spanish and Italian descent) and $3 \%$ is Mestizo (of mixed White and Indigenous race), Indigenous, or of another race $e^{(21,22)}$. Despite its significantly aging population, there have been no studies to date on AMD in Argentina, where epidemiological studies on blindness suggest that AMD may be the cause of $3-4 \%$ of blindness ${ }^{(20)}$. The objective of this case-control study is to assess the risk factors for the development and progression of AMD in Argentina.

\section{METHODS}

The study adhered to the tenets of the Declaration of Helsinki, and the IRB of the Fundación Hugo D. Nano in Buenos Aires, Argentina determined that it was exempt from formal IRB review.

Fundación Nano in Buenos Aires, Argentina contacted ophthalmologists throughout the country to participate in the study, and 28 participated, including 12 retina specialists and 2 general ophthalmologists. The ophthalmologists considered all new patients seen over a 2-month period in 2011 at their respective outpatient clinics for the survey on the possible risk factors of AMD provided that they did not have maculopathy. After patients voluntarily consented, surveys were conducted by their respective ophthalmologists during their consultations. The participating ophthalmologists and their subjects were from Buenos Aires City (the Federal Capital) and 5 interior provinces: Gran Buenos Aires, Santa Cruz, Santa Fe, Entre Rios, and Cordoba.

In the survey, subjects answered questions, when applicable, on their age, gender, race, iris color, systemic hypertension (defined as systolic blood pressure 2130 ), diabetes (Type I or Type II and type of treatment), cholesterol, status of AMD in each eye, family history of AMD, smoking and exposure to smoking, red meat consumption, fish consumption, and antioxidants intake. Weight, height, and abdominal diameter were measured at the time of the survey to calculate $\mathrm{BMI}$, and the status of AMD in each eye was also measured during the same consultation.

The treating ophthalmologists submitted the subjects to ophthalmological examination, classified AMD in each eye based on the standard classification of the disease, and also performed an Amsler grid test on each eye. Early AMD was classified as a presence of a few medium-sized drusen and/or pigment abnormalities ${ }^{(23)}$. Intermediate AMD was classified as a presence of at least one large drusen, numerous medium-sized drusen, and/or geographic atrophy that did not extend to the center of the macula. Advanced non-neovascular AMD was classified as presence of drusen and geographic atrophy extending to the center of the macula. Advanced neo-vascular AMD was classified as presence of choroidal neovascularization and any of its potential sequelae, including subretinal fluid, lipid deposition, hemorrhage, retinal pigment epithelium detachment, and a fibrotic scar ${ }^{(23)}$. Subjects with no history or signs of AMD were selected as controls.

Risk analysis was performed with a main effects model for logistic regression and ordinal logistic regression. Antioxidant status (taking antioxidants or not) was omitted from the potential list of variables because about 15\% of data were missing for the cases and controls. Age and gender were checked but not included in any simple logistic regression models as they are controlled for in the case matching. Race was categorized as White, Mestizo, and other (Indigenous, Black, or Asian), with White as reference. BMI was calculated by dividing weight in kilograms by the square of height in meters and categorized as being normal/slightly underweight (>18.5 kg/m $\mathrm{m}^{2}$ and $\left.<25 \mathrm{~kg} / \mathrm{m}^{2}\right)$, overweight $\left(25-29.9 \mathrm{~kg} / \mathrm{m}^{2}\right)$, and obese or morbidly obese $\left(\geq 30 \mathrm{~kg} / \mathrm{m}^{2}\right)^{(24)}$. Systemic hypertension was categorized as present or not, with no hypertension as reference. Diabetes was categorized as present (Type I or Type II) or not, with no diabetes as reference. Diabetes treatment was categorized as none, diet, oral drugs, and insulin, but treatment was only used if diabetes was a significant factor. Smoking was categorized as current smoker or not; packs per day $(0,<1,1-2$, or $>2)$; smoking years ( 0 years; $<10$ years; 10-20 years, and $>20$ years); and years of giving up smoking (0 years, $<10$ years, $10-20$ years, $>20$ years, and never smoked). Lives with smoker and lived with smoker were employed as dichotomous variables (present or not). Sunlight exposure was classified as an ordinal 2-level factor (light to moderate: 0-2 hours per day of sunlight exposure and moderate to heavy: +6 hours per day). Red meat consumption was classified as an ordinal 4-level factor (never, once a week, twice a week, and 3 or more times a week). Fish consumption was also classified as an ordinal 4-level factor (never, once a month, once a week, and 3 or more times a week). Iris color was categorized as brown, light to blue, and intermediate, with brown as reference. AMD was categorized as present or not for each eye. For the logistic regression, AMD was classified as present for the cases only and not for the controls. AMD type was categorized as none, dry, wet, or unknown, but was only used in the ordinal logistic regression. Fundus status for either eye was not used in the logistic regression.

In the logistic regression main effects model, all variables were initially entered into a single block, and those with a $p$ value $>0.15$ were removed. Non-significant variables $(p>0.05)$ were then removed singly with each remaining significant variable in a single block. Variables with a $p$ value less than 0.05 were significant. Retention of variables in the model was determined by Wald significance and block significance (chi square). Non-linearity of retained variables was not examined; for a small dataset these would need to be modeled in a mixed model although some idea of non-linearity could be obtained from the adjusted odds ratios (ORs).

In the ordinal logistic regression main effects model, the most severe AMD indication in either eye was taken as the score (1-4) for the dependent variable. All variables were entered into a single block and those with a $\mathrm{p}$ value $>0.05$ removed. The variables age and $\mathrm{BMI}$ categories were retained.

\section{RESULTS}

There were 175 cases and 175 controls, of whom 236 (67.4\%) were female. The mean ages of the cases and controls were 75.4 years (SD: 
7.75) and 75.5 years (SD: 7.87), respectively, showing that the cases were well matched to controls age-wise.

Of the cases, 154 (88.0\%) had AMD in their right eyes, 159 (90.9\%) had AMD in their left eyes, and 138 (78.9\%) had AMD in both eyes. Of the cases with AMD in their right eyes, 80 (51.9\%) had the dry type, 53 (34.4\%) had the wet type, and in 21 (13.7\%), the type was unknown. The comparable figures for left eyes were: 76 (47.8\%), 64 (40.3\%), and 19 (11.9\%), respectively. The severity of AMD in each eye is shown in tables $1 \mathrm{~A}$ and $1 \mathrm{~B}$ based on the complete data for each eye available at the time of analysis.

With regard to demographics of all subjects, 284 were White (81.1\%), 52 Mestizo (14.9\%), and 14 of other races (4.0\%). Fifty-eight percent reported on the surveys that they had systemic hypertension ( $n=203)$, and 49 reported to have diabetes (14.0\%), of whom 7 controlled their diabetes through diet (2.0\%), 38 through oral drugs (10.9\%), and 4 with insulin (1.1\%). Almost one-third of subjects had a BMI that indicated they were slightly underweight or of normal weight ( $n=116,33.1 \%), 142$ (40.6\%) were overweight, and 92 (26.3\%) were obese or morbidly obese. Fifty-four subjects (15.4\%) said they currently smoked, 40 subjects (11.4\%) said they currently lived with a smoker, and 105 subjects (30.0\%) said they previously lived with a smoker. Two-hundred-and-nine subjects (59.7\%) said they had never smoked, while 141 subjects had smoked at some point in their life, of which $53(15.1 \%)$ had given up for more than 20 years. Other data on smoking were too inconsistent to provide reliable results.

The majority had brown irises (222,63.4\%), while 80 (22.9\%) had light-to-blue color, and 48 (13.7\%) had intermediate color irises.

Fifty-two subjects (14.9\%) said they had a family history of AMD. The numbers were the same for those that had no family history or did not know ( $n=149$ each; $42.6 \%$ each).

The majority of subjects received moderate-to-heavy sunlight exposure $(n=247,70.6 \%)$, while only 103 (29.4\%) of subjects had light-to-moderate sunlight exposure. Fish and red meat consumption are shown in table 2.

The final main effects model in the logistic regression (Table 3 ) had a Nagelkerke $R^{2}$ of 0.267 , a Hosmer and Lemeshow test value of 0.578 , and an overall percentage of correct classifications of $68.9 \%$ (cut point 0.5).

Table 1. A) Severity of age-related macular degeneration in each eye for logistic regression analysis*

\begin{tabular}{lcc}
\hline AMD severity & $\begin{array}{c}\text { Right eye } \\
\mathbf{n}(\%)\end{array}$ & $\begin{array}{c}\text { Left eye } \\
\mathbf{n}(\%)\end{array}$ \\
\hline Early & $43(26.9)$ & $40(24.5)$ \\
Severe & $31(19.4)$ & $25(15.3)$ \\
Advanced non-neovascular & $32(20.0)$ & $43(26.4)$ \\
Advanced neovascular & $54(33.7)$ & $55(33.8)$ \\
\hline
\end{tabular}

${ }^{*}=$ the table above shows severity for the eyes with complete data at the time of the logistic regression analysis. Three eyes did not have complete data and were not included. $\mathrm{AMD}=$ age-related macular degeneration.

Table 1. B) Severity of age-related macular degeneration in each eye for ordinal logistic regression analysis"

\begin{tabular}{lcc} 
AMD severity & $\begin{array}{c}\text { Right eye } \\
\mathbf{n}(\%)\end{array}$ & $\begin{array}{c}\text { Left eye } \\
\mathbf{n}(\%)\end{array}$ \\
\hline Early & $43(26.9)$ & $38(23.8)$ \\
Severe & $31(19.4)$ & $25(15.6)$ \\
Advanced non-neovascular & $32(20.0)$ & $41(25.6)$ \\
Advanced neovascular & $54(33.7)$ & $47(29.4)$ \\
\hline
\end{tabular}

${ }^{*}=$ the table above shows severity for the eyes with complete data at the time of the ordinal logistic regression analysis. $\mathrm{AMD}=$ age-related macular degeneration.
Interpretation of the main effects model shows that it is dominated by higher sunlight exposure (OR: 3.3) and a family history of AMD (OR: 4.3) (Table 3). The unknown category for AMD family history was also very significant because it most likely contains many subjects who have a family history of AMD. Other factors include systemic hypertension (OR: 2.1) and smoking (OR: 2.2). Finally, being of the Mestizo race lowers the risk of getting AMD (OR: 0.40).

For the ordinal logistic regression, the final main effects model had a Nagelkerke $R^{2}$ of 0.263 , a model fitting $p$ value of $1.9 \times 10^{-7}$, with significant parameters listed in table 4 . In this ordinal logistic

Table 2. Fish and meat consumption

\begin{tabular}{lcc}
\hline Consumption rate & $\begin{array}{l}\text { Meat } \\
\mathbf{n}(\%)\end{array}$ & $\begin{array}{c}\text { Fish } \\
\mathbf{n}(\%)\end{array}$ \\
\hline Never & $26(7.4)$ & $94(26.9)$ \\
Once a month & - & $60(17.1)$ \\
Once a week & $80(22.9)$ & $134(38.3)$ \\
Twice a week & $137(39.1)$ & - \\
Three or more times a week & $107(30.6)$ & $62(17.7)$ \\
\hline
\end{tabular}

Table 3. Main effects model, logistic regression

\begin{tabular}{lccccc}
\hline Parameter & $\mathbf{B}^{*}$ & $\mathbf{S E}^{\dagger}$ & $\mathbf{P}^{\ddagger}$ & $\mathbf{O R}^{\S}$ & $\mathbf{9 5 \%} \mathbf{C l}$ \\
\hline Race & & & 0.016 & & \\
$\quad$ & & & & \\
$\quad$ Mestizo & -0.924 & 0.363 & 0.011 & 0.397 & $0.20-0.81$ \\
$\quad$ Other & -0.931 & 0.618 & 0.132 & 0.394 & $0.12-1.32$ \\
Hypertension & 0.752 & 0.247 & 0.002 & 2.122 & $1.31-3.44$ \\
Smoker & 0.782 & 0.357 & 0.028 & 2.187 & $1.09-4.40$ \\
Moderate-to-heavy & 1.188 & 0.275 & $1.5 \times 10^{-5}$ & 3.281 & $1.91-5.62$ \\
sunlight exposure & & & & & \\
AMD familial history & & & $7.8 \times 10^{-6}$ & & \\
$\quad$ Yes & 1.465 & 0.371 & $7.9 \times 10^{-5}$ & 4.329 & $2.09-8.96$ \\
$\quad$ Unknown & 1.067 & 0.263 & $5.1 \times 10^{-5}$ & 2.907 & $1.74-4.87$ \\
\hline
\end{tabular}

${ }^{*} \mathrm{~B}=$ logistic coefficients; ${ }^{\mathrm{t}} \mathrm{SE}=$ standard error; ${ }^{\ddagger} \mathrm{P}($ value $)=$ significance; ${ }^{5} \mathrm{OR}=$ odds ratio; $\| \mathrm{Cl}=$ confidence intervals. The reference for race is White, for hypertension no hypertension, for smoking status no smoking, for sunlight exposure light-to-moderate exposure (0-6 hours of sunlight exposure per day), and for age-related macular degeneration (AMD) familial history no history of AMD.

Table 4. Main effects model, ordinal logistic regression

\begin{tabular}{lcccc}
\hline Parameter & B coefficient $^{*}$ & $\mathbf{P}^{+}$ & $\mathbf{O R}^{\ddagger}$ & $\mathbf{9 5 \%} \mathbf{C l}^{\mathbf{5}}$ \\
\hline BMl category\| & & & & \\
$\quad$ Obese & -1.041 & $\mathbf{0 . 0 0 7}$ & 2.830 & $1.330-6.060$ \\
$\quad$ Overweight & $\mathbf{- 0 . 2 8 0}$ & 0.478 & 1.320 & $0.610-2.860$ \\
Age category (years) ${ }^{\boldsymbol{9}}$ & & & & \\
>84 & 3.859 & $5.6 \times 10^{-6}$ & 0.021 & $0.004-0.110$ \\
$80-84$ & 2.697 & 0.000045 & 0.067 & $0.018-0.250$ \\
$75-79$ & 2.020 & 0.001 & 0.133 & $0.039-0.450$ \\
$70-74$ & 1.593 & 0.012 & 0.203 & $0.059-0.700$ \\
$65-69$ & 1.042 & 0.117 & 0.353 & $0.096-1.300$ \\
\hline
\end{tabular}

${ }^{*}=$ coefficients for the predictor variables; ${ }^{\dagger} \mathrm{P}$ (value)= significance; ${ }^{\ddagger} \mathrm{OR}=$ odds ratio; ${ }^{8} \mathrm{Cl}=$ confidence intervals; "BMl= body mass index reference is normal or slightly underweight $\left(18.5 \mathrm{~kg} / \mathrm{m}^{2}\right.$ and $\left.<25 \mathrm{~kg} / \mathrm{m}^{2}\right)$; ${ }^{*}$ reference is $<65$ years. 
regression, an $\mathrm{OR}>1$ means an association with a lower score or less AMD severity, while an $O R<1$ indicates an association with higher scores or higher AMD severity.

As expected, age shows a steady dose-response relationship with higher age associated with progression to more severe AMD. Higher BMI, however, appears somewhat protective in AMD progression (only obese BMI is significant), which might indicate selection bias, but the explanation for this is unknown.

\section{DISCUSSION}

Increased sunlight exposure and a family history of AMD were the most significant risk factors in developing AMD that were observed in this study in addition to hypertension, smoking, and being white. An older age was a significant risk for disease progression.

Sunlight exposure has produced inconsistent results as a risk factor in other research. A study carried out in the South of France, which used ambient solar radiation to test for an association of more sunlight exposure with AMD, did not conclude that there was an effect; however, a Canadian study considered sunlight exposure to be a possible risk factor ${ }^{(5,25)}$.

For family history, the results of the unknown variable (OR: 2.9) are also significant and suggest that many of these subjects may indeed have a family history of AMD. It is, therefore, very important that greater attention in Argentina be given to raising awareness of AMD and its risks not only with subjects, but with their families, who should be informed of the association between family history and AMD. These results and recommendations were also confirmed by another case-control study in the UK, which found that family history was associated with a 12-fold increase in the odds for disease ${ }^{(3)}$.

Being of the Mestizo race reduces the risk of developing AMD (OR: 0.40). Other Hispanic populations have also been found to have a reduced risk of developing late $\mathrm{AMD}^{(9)}$. The US National Health and Nutrition Examination Survey III was a national representative population-based, cross-sectional study that looked at the prevalence and risk factors for AMD in non-Hispanic whites, non-Hispanic blacks, and Mexican Americans. The rates were overall not very different, but late AMD was higher among whites. White and black women were more likely to develop it then their male counterparts. However, Mexican-American women did not have an increased risk ${ }^{(9)}$. That said, the proportion of the Mexican population that is Mestizo is $60 \%$, and only $9 \%$ is white, whereas $97 \%$ of the population of Argentina is White and only $3 \%$ is Mestizo, Indigenous, or of another race ${ }^{(22)}$. (It should be further noted that the majority of subjects in this study were white (81\%), which is a close representative proportion of the demographics of the country). Therefore, from a national, demographic perspective, almost the entire population of Argentina has an increased risk of developing AMD.

It is interesting to note that red meat consumption, fish consumption, BMI, and iris color did not result in an association with AMD. The previously mentioned Canadian study determined that family history, obesity, and smoking were significant risk factors, and a lighter colored iris (and sun exposure) was a possible factor ${ }^{(5)}$. Fish consumption as a risk factor has also produced mixed results in other studies. Studies in the United States (US) and Australia found that fish consumption reduces the risk of developing AMD, whereas another cohort in Australia did not find any significant association (26-29).

An older age was the significant risk factor for progression to more severe AMD. It was not clear, however, why a higher BMI, with the exception of the obese category, seemed to reduce the risk. Another study found that a greater BMI, waste circumference, and waist to hip ratio increased the risk for progression to late $\mathrm{AMD}^{(30)}$.

This case-control study was the first investigation of AMD in Argentina, and the results of the study mirror to an extent the risks factors concluded in other work. There were, however, some limitations that may have impacted the results. Subjects were not randomly selected for participation. The methodology for obtaining the data relied heavily on follow-up personal communications between the researchers and the participating ophthalmologists. Unfortunately, incomplete data were not uncommon. Undiagnosed diabetes and systemic hypertension might bias their respective association with AMD. It should also be noted that the classification response (not shown) was not that good, so there may be other variables that are needed in the risk analysis model. The sample size was also small; a larger sample size with more participating regional eye care programs would perhaps provide a broader perspective to the risk factors of AMD in Argentina, more data, and different significant variables. In the ordinal logistic regression, a test for parallel lines could not be run because convergence could not be attained or ascertained in estimating the general model. The levels of the variables were still plotted (not shown), and in both instances were distinctly non-parallel, which is a limitation of this model. The existing factors seemingly do not explain very well the risk of developing AMD, but these factors also produced inconsistencies among previous studies.

Sunlight exposure, family history of AMD, and being older were the significant risk factors for the development and progression of AMD revealed in this case-control study in Argentina. There may be other variables, as the risk was not explained very well by the existing factors. However, apart from age and family history, the literature search generally demonstrated conflicting results from one study to the next, which may suggest that risk factors are specific to each population in each of their environments, based on the variable exposures. A future study in Argentina that uses a larger sample may produce different, stronger, and/or better results.

\section{ACKNOWLEDGEMENTS}

The authors would like to thank ORBIS for their financial support of the study.

The authors would also like to thank all the ophthalmologists who helped collect the data.

Andrea Aguilar - Buenos Aires Province, Inés Balogh-Kovacs - Buenos Aires Province, Agustina Borrone - Buenos Aires Province, Santiago Castro Feijoó - Buenos Aires Province, Estanislao Cima - Buenos Aires Province, Claudia Colodro Guillén - Buenos Aires Province, Edgardo De Mauri - Buenos Aires Province, Ricardo Goñi - Buenos Aires Province, Natalia Menarini - Buenos Aires Province, David Moreno Figueredo - Buenos Aires Province, Federico Morriello - Buenos Aires Province, María Eugenia Pais - Buenos Aires Province, Enrique Paz - Buenos Aires Province, Marcelo Rivamonti - Buenos Aires Province, José Tintel Pantich - Buenos Aires Province, Claudio Juarez - Santa Cruz Province, Joaquín Bafalluy - Santa Fe Province, Guillermo Navarro - Entre Rios Province, José Luna Pinto - Cordoba Province, Eduardo Zábalo - Cordoba Province, Rafael Iribarren - Buenos Aires City - Federal Capital, David Pelayes - Buenos Aires City - Federal Capital, Pablo Rivera - Buenos Aires City - Federal Capital, Marcelo Zas - Buenos Aires City - Federal Capital, Andrés Bastién - Buenos Aires City - Federal Capital, Carmen Demetrio - Buenos Aires City - Federal Capital, Guillermo Iribarren - Buenos Aires City - Federal Capital.

\section{REFERENCES}

1. Pascolini D, Mariotti SP. Global estimates of visual impairment: 2010. Br J Ophthalmol. 2012:96(5):614-8

2. World Health Organization. Global data on visual impairments 2010. Geneva: World Health Organization; 2012. [cited 2012 Dec 20]. Available from: http://www.who.int/ blindness/GLOBALDATAFINALforweb.pdf.

3. Shahid H, Khan JC, Cipriani V, Sepp T, Matharu BK, Bunce C, Harding SP, Clayton DG, Moore AT, Yates JR; Genetic Factors in AMD Study Group. Age-related macular degeneration: the importance of family history as a risk factor. Br J Ophthalmol. 2012; 96(3):427-31.

4. Bressler NM. Age-related macular degeneration is the leading cause of blindness. JAMA. 2004;291(15):1900-1. Comment on Arch Ophthalmol. 2004;122(4):564-72.

5. Cruess AF, Berger A, Colleaux K, Greve M, Harvey P, Kertes PJ, et al. Canadian expert 
consensus: optimal treatment of neovascular age-related macular degeneration. Can J Ophthalmol. 2012;47(3):227-35. Erratum in Can J Ophthalmol. 2012;47(5):460.

6. Klein R, Klein BE, Linton KL. Prevalence of age-related maculopathy. The Beaver Dam Eye Study. Ophthalmology. 1992;99(6):933-43.

7. Mitchell P, Smith W, Altebo K, Wang JJ. Prevalence of age-related maculopathy in Australia. The Blue Mountain Eye Study. Ophthalmology. 1995;102(10):1450-60.

8. Vingerling JR, Diclemans I, Hofman A, Grobbee DE, Hijmering M, Kramer CF, et al. The prevalence of age-related maculopathy in the Rotterdam Study. Ophthalmology. 1995;102(2):205-10. Comment in Ophthalmology. 1996;103(2):196-7.

9. Klein R, Klein BE, Jensen SC, Mares-Perlman JA, Cruickshanks KJ, Palta M. Age-related maculopathy in a multiracial United States population: the National Health and Nutrition Examination Survey III. Ophthalmology. 1999;106(6):1056-65.

10. Gupta SK, Murthy GV, Morrison N, Price GM, Dherani M, John N, et al. Prevalence of early and late age-related macular degeneration in a rural population in northern India: the INDEYE feasibility study. Invest Ophthalmol Vis Sci. 2007;48(3):1007-11.

11. Krishnaiah S, Das T, Nirmalan PK, Nutheti R, Shamanna BR, Rao GN, et al. Risk factors for age-related macular degeneration: findings from the Andhra Pradesh eye disease study in South India. Invest Ophthalmol Vis Sci. 2005:46(12):4442-9.

12. Xu L, Li Y, Zheng Y, Jonas JB. Associated factors for age related maculopathy in the adult population in China: the Beijing eye study. Br J Ophthalmol. 2006;90(9):1087-90. Comment in Br J Ophthalmol. 2006;90(9):1073-4.

13. Cheung N, Wong TY. Changing trends of blindness: the initial harvest from translational public health and clinical research in ophthalmology. Am J Ophthalmol. 2012; 153(2):193-5

14. Roston E, McKibbin M. Visual impairment certification secondary to ARMD in Leeds, 2005-2010: is the incidence falling? Eye (Lond). 2012;26(7):933-6

15. Skaat A, Chetrit A, Belkin M, Kinori M, Kalter-Leibovici O. Time trends in the incidence and causes of blindness in Israel. Am J Ophthalmol. 2012;153(2):214-21.e1.

16. Bloch SB, Larsen M, Munch IC. Incidence of legal blindness from age-related macular degeneration in Denmark: year 2000 to 2010. Am J Ophthalmol. 2012;153(2): 209-13.e2.

17. Klein BE, Klein R. Forecasting age-related macular degeneration through 2050. JAMA. 2009;301(20):2152-3.

18. Seddon JM, Reynolds R, Maller J, Fagerness JA, Daly MJ, Rosner B. Prediction model for prevalence and incidence of advanced age-related macular degeneration based on genetic, demographic, and environmental variables. Invest Ophthalmol Vis Sci. 2009;50(5):2044-53.
19. Seddon JM, Reynolds R, Yu Y, Daly MJ, Rosner B. Risk models for progression to advanced age-related macular degeneration using demographic, environmental, genetic, and ocular factors. Ophthalmology. 2011;118(11):2203-11.

20. Furtado JM, Lansingh VC, Carter MJ, Milanese MF, Peña BN, Ghersi HA, et al. Causes of blindness and visual impairment in Latin America. Surv Ophthalmol. 2012;57(2): 149-77.

21. United Nations, Department of Economic and Social Affairs. Population Division, Population Estimates and Projections Section. World Population Prospects, the 2010 Revision. Stamdar variants (Updated: 28 June 2011). [cited 2012 Oct 29]. Available from: http://esa.un.org/wpp/Excel-Data/population.htm.

22. Central Intelligence Agency. The World Factbook 2012. Washington, DC: Central Intelligence Agency; 2012. [cited 2012 Nov 1]. Available from https://www.cia.gov/ library/publications/the-world-factbook/index.html.

23. Jager RD, Mieler WF, Miller JW. Age-related macular degeneration. N Engl J Med. 2008; 358(24):2606-17. Review. Erratum in: N Engl J Med. 2008;359(16):1736.

24. World Health Organization. Global strategy on diet, physical activity, and health [cited 2012 Dec 19]. Available from: http://www.who.int/dietphysicalactivity/child hood_what/en.

25. Delcourt C, Carrière I, Ponton-Sanchez A, Fourrey S, Lacroux A, Papoz L; POLA Study Group. Light exposure and the risk of age-related macular degeneration: the Pathologies Oculaires Liées à I'Age (POLA) study. Arch Ophthalmol. 2001;119(10): 1163-8.

26. Chong EW, Robman LD, Simpson JA, Hodge AM, Aung KZ, Dolphin TK, et al. Fat consumption and its association with age-related macular degeneration. Arch Ophthalmol. 2009;127(5):674-80.

27. Christen WG, Schaumberg DA, Glynn RJ, Buring JE. Dietary $\omega-3$ fatty acid and fish intake and incident age-related macular degeneration in women. Arch Ophthalmol. 2011;129(7):921-9.

28. Tan JS, Wang JJ, Flood V, Mitchell P. Dietary fatty acids and the 10-year incidence of age-related macular degeneration: the Blue Mountains Eye Study. Arch Ophthalmol. 2009;127(5):656-65.

29. Seddon JM, George S, Rosner B. Cigarette smoking, fish consumption, omega-3 fatty acid intake, and associations with age-related macular degeneration: the US Twin Study of Age-Related Macular Degeneration. Arch Ophthalmol. 2006;124(7):995-1001.

30. Seddon JM, Cote J, Davis N, Rosner B. Progression of age-related macular degeneration: association with body mass index, waist circumference, and waist-hip ratio. Arch Ophthalmol. 2003;121(6):785-92. 